\title{
1 Introduction: Spacing Whiteness in Improv
}

\subsection{Lacking object and discipline}

This project originated in the observation that the vast majority of people who practice improv comedy or improvised theater are white, while other improvisational or comedic art forms (jazz, freestyle rap, stand-up) are historically grounded in and marked as Black cultural production. ${ }^{1}$ What is it about improv, which I know and practice, that makes it such a white space? But can an absence be an object of study - in this case Black absence? If so, what is there to study? Where should one look? And what would it mean to take improv as my object? Improv is a multifaceted and multidimensional phenomenon. When I use the term, I refer to its communal dimension (of a particular school, a local community, or the global improv community) as well as its aesthetics and aesthetic procedures. My usage encompasses how these play out in the theatrical situation of performance, its history and historiography, and the discourses that bring improv about and that it generates, such as manuals, articles, books, online discussions, and podcasts. I also denote its underlying Humanist assumptions, the performative role it plays within popular culture, and the way popular culture's social function feeds back into the cultural phenomenon of improv. One of the first questions that long stupefied me was how to disentangle improvisation as an aesthetic practice - more mode than content - from the ethical and political issues towards which Black absence points in loud silence. For too long, I adhered to the logic that improvisation was merely an aesthetic modality free of content that didn't mean in itself, and consequently didn't provide a ground for discussion outside homogenizing ascriptions to the absent group. Eventually, I came to realize that this colorblindness is part of the problem: Theatrical improvisation

1 Throughout, I capitalize Black, Blackness, and terms that include these words - such as antiBlack racism - to mark their reference to a discursive construct rather than an empirical existence, which is not to say that those do not reciprocally affect each other. I refer to a signifier created by white people that, in my usage, has no ontological or essentialist content value and denotes no empirical referent. Again, this is not to say that those who are racialized as Black (in Nathaniel formulation) are somehow indescribably unreal. The decision is a situated one: As a white scholar, I do not intend to make existential or ontological statements about what it might mean to live Blackness. Epistemologically, I am restricted to analyzing the creation and functioning of the signifier, not those signified. Black Studies scholars mostly use the lower case - and they are in the position to do so. As a white subject, I can make such existential (even ontological) statements only about whiteness or what white people do, so I use lower case for white or whiteness.

Ә OpenAccess. (C) 2022 Michel Büch, published by De Gruyter. (cc) BY-NC-ND This work is licensed under the Creative Commons Attribution 4.0 International License. https://doi.org/10.1515/9783110752748-002 
does not see color because it is color. ${ }^{2}$ As a theatrical mode and in the history of its aesthetics and practices, improvisation is white, and continually sets up whiteness as a categorial default invisible to the white improviser. Thus, the question "Why are there so few Black improvisers?" becomes "How does improv continually constitute itself as a white space?” The ease with which improv discourse and practice provide a seemingly ahistorical grammar allows white improvisers to fancy their improv beyond the limitations of cultural and situated knowledge. Maintaining a focus on the subtle and not-so-subtle ways in which improv reasserts its whiteness is a challenge.

I am concerned in this project with the auto-institutive, or self-engendering, machinations of improv's whiteness understood as continual anti-Black abjection. The project is thus an attempt at white autocritique. However, where exactly is one to look in order to find the auto-institutive mechanics of improvisation? How does one lay bare the dynamics that underlie the superficial racial stereotypes performed on stage for everyone to see? What distinguishes improv from other forms of representational comedy or live theater? Previous scholarship on improv is of no help in answering these questions. Only one source deals explicitly with improv's dominance by white males: Amy Seham's 2001 Whose improv is it anyway? Seham's book has been ignored in academic discourse on improv and despised by the white majority of improvisers because it calls out racism and sexism. Most improv scholarship is written by improvisers themselves; it is always celebratory or seeks to demonstrate how improvisation and its principles can be applied in contexts other than the stage. Improvisation is written into theater historiography (see J. Coleman or Wasson), or used as a traveling concept at anybody's disposal; in theory, improv solves anything. Such theorization is aimed at legitimizing improv as an art form proper, designed to raise it to a level worthy of academic consideration simply by the act of considering it within the terms of the academy. This assertive approach is a problem for improv theory, which usually aligns concepts by analogy in one of two patterns of argumentation. One describes non-improv activities or behavior as improvisation or maps improv's poetic principles (such as the "yes, and" principle) onto non-aesthetic domains. The other applies academic concepts to improv, such as suggesting that in improv, we can see emergence at work. Both patterns are uncritically

\footnotetext{
2 Aside from the titles of publications, I use italics to mark emphasis (as in this case) or to draw attention to a specific word in context. The latter sometimes involves semi-ironic nuances, not for humorous reasons but to highlight that the term a) is insufficient or inadequate for what is needed, similar to Derrida's erasure, b) reverberates with points previously discussed, or c) is polysemous and points out of its specific use and context toward something larger. I emphasize some words in quotations in the same way, and mark that emphasis.
} 
in favor of improvisation and foreclose any critical treatment of the subject. In their attempt to generate universal knowledge, they rarely account for improv's less appealing realities.

However, neither its healing powers nor the application of improv's concepts to the non-improv world incited my inquiry. Disposing of these celebratory approaches, I looked at ways I could think about improvisation in less idealized terms around communicational practice, starting from familiar concepts of sending, receiving, gatekeeping, and so on. While I am still sympathetic to such close readings of an improv scene and of the modal aesthetics of improv, this approach soon proved to be too clinically objective; I found myself caught up in the intricacies of communicational concepts and the ill-fated ideal of methodological objectivity at all costs, which always derailed the analysis from my initial question. In every kind of allegedly objective methodology, I was missing something and I had a hunch it would never be enough. I realized that in using an aesthetic analysis that dealt with improvisation alone, I would never get to the core of improv's whiteness beyond the fact that white people always produce material based on and alluding to their shared white reality. That this reality is not universal is one of the central obstacles Black improvisers face in Chicago, as Aasia LaShay Bullock ${ }^{3}$ and Dewayne Perkins ${ }^{4}$ suggest:

Bullock: It's so easy to imagine that the white experience is the neutral experience. That it's the experience everybody has. I actually didn't have that experience.

Perkins: I was on a team in a theater. And they were talking about dad jokes, and we named our team "Daddy." They're like, "Oh, we should take pictures dressed up as fathers with Khakis!” And I was like, “My father doesn't dress like that. I don’t know how to tell those jokes either."

Bullock: That happens all the time. "Like mums do." And I'm like, "I don't know what that means. Explain to me. It never even occurred to you, because I'm sure all the mums you

3 Aasia LaShay Bullock is an LA-based comedian, writer, actress, singer, dancer, rapper, and music producer. Her web series Starving Artists won several awards at the 2017 New York Television Festival, among them "Best Short Form Digital Project." Most recently, she wrote for Upload (2020, Amazon Prime) and Space Force (2020, Netflix). Find out more on her personal website. Our conversation took place in March 2015 in Chicago, together with Dewayne Perkins. Bullock authorized the material used in this project via email on 6 October 2019.

4 Dewayne Perkins is an LA-based writer and comedian born and raised in Chicago. He won “Just For Laughs New Faces of 2019," and currently writes for NBC's Brooklyn Nine-Nine. He also wrote the Comedy Central web short The Blackening for the comedy collective 3peat, of which he is a member. The Blackening became a viral success with more than 15 million views. Find out more on his personal website. Our conversation took place in March 2015 in Chicago. Perkins authorized the material used in this project via email on 7 October 2019. 
know did do that. None of the mums I know did. Guess what all your life is wrong. Let me shatter it a little bit. Let me tell you about my childhood.” (personal conversation)

None of my go-to disciplines promised any significant results beyond the superficial critique of situated knowledges or culturally specific ignorance. Therefore, I decided to let go of disciplinary boundaries and trust my own (instinctive? intuitive?) knowledge about improvisation - as flawed and white-inflected as that must necessarily be.

Based on many years of improv practice and readings of improv literature, I have come to think of improv through three central concepts: a) intuition, because we do not have a lot of time to make decisions on the stage, and so rely on whatever helps us make them quickly, b) play, which is the primary descriptor of what we do, and c) humor, which is the most prominent outcome and aim of improv, at least in its US comedy version - despite some decidedly process-oriented artists and academic treatments that focus purely on its aesthetic dimension. Theories and practices of intuition, play, and humor all foreground some notion of the Human or involve statements about human existence. ${ }^{5}$ They all feature some sort of celebration of the Human self. Recognizing this shared conceptual ground spurred my selection of the project's theoretical groundwork. The set of perspectives and concepts essential to this project includes Sylvia Wynter's elaboration of the modern West as a culturally specific construct that makes itself invisible to its cultural subjects; Sabine Broeck's concept of anti-Black abjection, which describes the continual dehumanizing anti-Black violence necessary for maintaining the white position as default; and Afro-pessimist points of critique put forward by Frank Wilderson. This deconstructive approach towards epoch-making Western Humanism, its repercussions, and the concepts used to describe them provides the theoretical and axiomatic ground for my three investigatory frames of intuition, play, and humor. Initially, I treated these frames separately, without any methodological guidance beyond grounding them in improv discourse and practice. However, in the process, I discovered that the language of psychoanalysis could be used to discuss what happens in improv in these respective fields. While they went in different directions, over the course of this project they became more and more interlaced, so that an unanticipated thread came to the fore. This project, then, is the conscious performance of making theory as opposed to applying concepts and presenting the results, proving or dis-

5 I use the upper case for Human, Humanity, and Humanism when I refer to the cultural specificity of the modern subject, drawing attention to its status as a (semiotically arbitrary) discursive construct. 
proving a thesis that may or may not have been part of a larger theoretical or political agenda. I bring into tense conversation previously unrelated or even disconnected theories and models of thought, keeping the argument always tethered to the grounds of an observed anti-Blackness in improv. This is original work in that it creates arguments about the relationship between anti-Blackness and improv that no single theory or allegedly objective methodology has yet provided or could provide.

This is not to say that I am not deeply indebted to previous scholarship as well as to those improvisers who have shared their perspectives and experiences with me. I am entirely dependent on critical race studies, theories of embodied cognition, psychoanalysis, and many more, as much as I rely on various manifestations of the improv discourse from without and from within. The latter includes a list of practicing (then) Chicago improvisers and comedians willing to share their (non-homogenous) thoughts, positions, and experiences with me, allowing me to use them here as well. The list includes renowned professional improvisers, young artists at the beginning of their careers, and everything in between. I have taken care never to analyze the interviewees or their contributions, but engage with them as interlocutors, cue-givers, and experts on the workings of the (Chicago) improv scene. They are never the object of analysis, but are rather on the team of analysts so to speak, even though I ultimately place their contributions dramaturgically in the logic of my argument. Nonetheless, I have taken great care not to present quotes out of context, instead maintaining their semantic and argumentative environment and retaining their autonomy as far as possible. This is why some quotations are rather lengthy. Where I did use only brief selections or turns of phrases, I checked to ensure I wasn't doing interpretive violence to their contribution. And yet, I am fully responsible for all shortcomings in this project, ethical and theoretical. As difficult as this terrain will prove to wander, I think this is the only way to talk about improv, given the lack of an object proper. The mere application of a closed theoretical framework, in terms of a mechanically consistent methodology, would bring a faulty order to the mess of reality and is thus predisposed to repeat the anti-Black acts of violence it aims to critique. Violence in the name of objectivity has done enough harm in the humanities.

\subsection{Barthes's punctum as methodology}

Given the absence of an object (or one with clear and observable borders), I develop a methodological procedure with recourse to Roland Barthes's notions of the studium and the punctum in his Camera Lucida (1981). Barthes sets out to 
develop a theory of photography, seeking an ontology of photography itself but soon discovering that photography as such is unclassifiable - as is improv. Its ontology cannot be reduced to separate, categorial units because there is no rule to determine the significant questions. Would they be empirical, rhetorical, aesthetic? In discussing the racial structures of improv, the same difficulties arise: do I consider institutions, empirical facts, rhetorical devices, sociological questions, tropes within the discourse, performance style, aesthetic foundations? What could the theoretical or disciplinary frame be? Should the work be semiological, sociological, psychoanalytical (8)? Leaving these questions aside, Barthes provides the pair of studium and punctum, which I will briefly introduce as a methodological model. The studium refers to the general meaning of a picture observed by a curious but rarely affected spectator. The punctum, in contrast, denotes a specific detail of the image that breaks through (punctures) the studium. The studium is an average and intended effect on the spectator, recipient, or reader, whereas the punctum is subjective, affective, and specific. The studium thus refers to what could also be called the hegemonic meaning in accordance with a dominant ideology, that is, the frame or discourse within which the image or discursive unit communicates and is shared by the assumed recipient as a quick decoder of its meaning. The studium gives us content-oriented encoded information. ${ }^{6}$ The punctum, on the other hand, "shoots out of [the scene of the studium] like an arrow, and pierces me" (26). Punctum literally means "sting, speck, cut, little hole," making it "that accident which pricks me (but also bruises me, is poignant to me)" (26-27). The punctum is a detail that disturbs the studium, the mere presence of which "changes my reading" (42). What gives the punctum a kind of methodological impact and workability is its "power of expansion," which is "often metonymic" (45). The impact of the punctum is unintended, yet never accidental: "Hence, the detail which interests me is not, or at least is not strictly, intentional, and probably must not be so; it occurs in the field of the photographed thing [i.e., the analyzed object] like a supplement that is at once inevitable and delightful" (47). The punctum also speaks to an absence of the studium at large. Barthes claims that the "punctum, then, is a kind of subtle beyond - as if the image launched desire beyond what it permits us to see" (59). What narratives other than the studium (even running counter to it) can be read from the text when one departs from the singular punctum? What more extensive logic can be unraveled from this specific detail? What

6 For further clarity: “To recognize the studium is inevitable to encounter the photographer's intention, to enter in harmony with them, to approve or disprove of them, but always to understand them, to argue them within myself, for culture (from which the studium derives) is a contract arrived at between creators and consumers" (Barthes 28). 
makes it stand out (for me)? These punctum-focused readings will be applied as an investigative modality throughout this project, directed at elements immediately drawn from the world of improv as well as theoretical and ideological assumptions and concepts on which improv discourse rests.

In this study, I transpose these two concepts into the textual units of culture (culture-as-text) by engaging with the studium level to show the tropes around which improv positively writes itself into being, or to provide the background against which the punctums attain their effects. Sometimes it is a punctum or an absence that drives a close reading. Raising Barthes's dual model to the rank of a method also qualifies my project's position and its argumentational devices and strategies. Developing a methodology out of Barthes's concepts has implications. He acknowledges that the choice of analytical units and the allocation of their respective relevance to each other are always based on an affective/emotional "I like / I don't like: we all have our secret chart of tastes, distastes, and indifferences, don't we" (18)? The subjective evaluation of the scholarly I itself is very much central to any study (including this one). Barthes's approach is then to "remonstrate my moods; not to justify them; still less to fill the scene of the text with my individuality; but on the contrary, to offer, to extend this individuality to a science of the subject, a science whose name is of little importance to me" (18). He further writes that admitting one's subjective-affective punctums as examples at times involves "giv[ing] myself up" (43). Because a punctum is defined by a retrospective, emotional, and affective effect of the spectator or reader, it "shows no respect for morality or good taste: the punctum can be ill-bred" (43). These implications are valid for other scholarly enterprises as well, regardless of how objective, scientific, or methodologically accurate they fancy themselves. Such objectivity is part of the structure that veils and makes opaque the whiteness tacitly assumed to be a center of normalcy. With Barthes, we white scholars can carry our own positionality out into the open, without fancying ourselves in the position to disentangle our scholarly choices, the specific selection of our examples, and the general thrust of our argument. Even suggesting that I could put forward such an individual (not systemic) autoanalysis would undermine my central arguments.

The transposition from an emotional reaction to a text to its academic evaluation is purely heuristic. Thus, in a potentially devastating return to Barthes's foundational I like / I don't binary, this project is always vulnerable to criticism that positions it alongside other examples of white agents feeding on fetishized Blackness. Barthes himself is an example, even in the development of the studi- 
um-punctum concept. ${ }^{7}$ And yet, because of our own white positional and affective grounds, how can we white scholars align our work with Afro-pessimist theory in a meaningful way, both in terms of strategy and with our own affective life? How can we put into words the intellectual reaction to and analysis of a real-world example or fictional story that generates disgust and repugnance but helps to develop, illustrate, illuminate a theory? Barthes has the same question, asking himself whether he could "retain an affective intentionality, a view of the object which was immediately steeped in desire, repulsion, nostalgia, euphoria" (21). How can we keep ourselves in check if we are not even reliably aware that we are performing anti-Blackness in our choice of examples or objects, in the racially ignorant application of inherently raced concepts or in our use of language? Why would the white scholar be in any way different from the white agent who is the subject of critique?

\subsection{White performance of Afro-pessimism}

Positionality and affect must be considered because Afro-pessimist performance - academic or other - takes on different meanings depending on the scholar who uses it. White thought in an Afro-pessimist framework is a paradoxical practice. We must ask whether the application (appropriation? obliteration?) of Afro-pessimist theory by white people can be something other than a transumed version of the "white desire to consume the spectacle of Black death" (Sharpe par. 100). Christina Sharpe addresses the different ways in which Black scholars and white scholars approach the theory, predetermined by their respective positionalities:

I think that the only people who can be Afropessimists are non-Black people. I don't think Black people can actually be Afropessimists; my colleague, Kara Hunt, reminded me of this. We can theorize, we can meditate on Black suffering, we can experience the violence, we're marked. But we cannot be Afropessimists since the idea and reality of being is foreclosed to us: we're non-being. The only people who can be and embrace it are particularly these white, male, young academics who are so excited. They are excited by it. And it's an invigorating theory because it's a purely intellectual enterprise for them. (par. 81)

Sharpe speaks an uncomfortable truth for white male academics like myself. Merely pointing out this positional impasse does not solve the problem that a

7 Consider Barthes's analysis of his affective reaction to "a family of American Blacks, photographed in 1926 by James Van der Zee” (43). 
white scholar working with Afro-pessimist thought is in an ethically impossible position. ${ }^{8}$ This paradox is only viable in the white supremacist system that provides me the privilege of speaking against my own position without actually annihilating myself, or better, where self-annihilation is a "purely intellectual enterprise." Is there any way in which this acknowledgment can be made constructive for the present project? Is asking this question part of the problem?

Firstly, the concepts and theories put forward by predominantly Black theorizers are not necessarily related to an ontological Black culture. Afro-pessimism is concerned with how Western society comes up with and engenders the concept of Black culture in the first place. My purpose is not to find out about Black culture, but to consider Western improv culture and its anti-Black abjectorship as its foundational and structuring principle. Theorizers of Afro-pessimism have analyzed these processes on an epistemic level, and it is here that white scholars need to learn from them, being willing students to "epistemic lessons in redress" (Broeck, Abjection 40). Theories put forward by Afro-pessimist thinkers are not ethnographic material provided by native informants and must not be treated as such. Secondly, as a white scholar, I do not intend to explicate or summarize Afro-pessimism but to listen to its thinkers and hopefully put its concepts to good use. The social position I inhabit precludes me from becoming an expert or attaining authority in the field. In writing and speaking from a white position on subjects related to white ignorance (as conceived of by Charles Mills), I am bound to make mistakes of different degrees and gravity. I am bound to trip over language all the time because no language is adequate to addressing the issues at hand, and if it were, it would not be comprehensible to me as a white subject. The language and knowledge I can mobilize is constitutive of the complex of problems I am setting out to discuss. Yet I believe it is better to engage in that messy discussion than do away with it in a mere nod of acknowledgment. Maybe there is a way to generate an argument out of white shame that does not end in issues of guilt or morality at large. Understanding the system in which I am positioned seems to be the best step towards building solidarity. This piece is therefore an attempt to be spoken-to by Black knowl-

8 Notions of ethics, possibility, and positionality are already deeply ingrained in the problematics I discuss. In many ways, such a statement is not true, because whiteness is the very structure that provides its subjects positionality for the obliteration of Black scholarship without any ethical queries or other sanctions. However, I leave the sentence accompanied by this footnote to show that the language available is itself imbricated with the epistemic violence under analysis. Any attempt to use it amounts to the deployment of the master's tools, to echo Audre Lorde. This is especially relevant when used by white scholars who fantasize about dismantling our own house. 
edges and to listen, learn, and be vulnerable. To produce scholarship cautiously and with humility in and as practice. I do not invent, discover, or explore.

Positional specificity demands of the white scholar working with and using Afro-pessimism a constant alertness to the ways in which their writing as performative articulation are energized and inhibited by this configuration. This also relates to vulgar misreadings of such theorization as either entirely liberational and inspiring or as the epistemologically pessimist dead end it posits. At the same time, the white scholar must keep in mind how this alertness is in itself not particular but structurally libidinal. How do reporting on, foregrounding, and being the problem intersect? What is the performative effect of a white-positioned scholar who works with Afro-pessimist theory? In this context, it is important to note that as a white-bodied writing agent, I can (and should) say little to nothing about Black life, but I can say a lot of things about white structures of feeling that create Blackness as a signifier. While the sign is my creation, the referent is foreclosed to me. As a white-positioned author, I must be especially careful not simply to draw from an Afro-pessimist toolbox at will (will being a white privilege) and turn Afro-pessimist theory into a phrasebook. There is a genuine danger that terms, collocations, or phrases be applied carelessly and turned into hollow clichés. What does it mean for the white scholar to look into the abyss when they have no affective understanding of it because, for them, it does not exist? This is similar to the clichéd gesture of pointing out, which functions transitively to point certain elements of Afro-pessimist discourse and theory out of the way without actually reckoning with their consequences, or actively walking the theoretical space opened up by them. Pointing out denotes a gesture that allows the white scholar to speak without repercussion.

Further, Afro-pessimism demands a register incompatible with Humanist ways of reading and making the world, which involve concepts based on relationality and hope such as ethnicity, minority, diversity, and even difference writ large. In fact, in several sections of this project, this register becomes the object of critique. However, improv discourse manifests itself in these very registers. Critical positions regularly critique a lack of diversity or issues of representation. I do not wish to be the white scholar who comes along and applies a register that overrules the one applied by those who live the lives of Black improvisers in Chicago. Rather than whitesplaining the positions of my conversation partners, I draw on concepts located in the respective register of speech to address and value the material (opinions, anecdotes, and more). It is only in a second step that I move towards a different argumentational realm. What may appear a theoretical inconsistency in some sections of this project is my way of being spoken-to. 
The impossibility of my knowing race-based dehumanization viscerally except from the abjector's point of experience confines the extent to which I can engage with it. However vague this may appear, I do believe that the concept of visceral, embodied knowledge is of crucial importance in the debate for Black authority on the subject. The knowledge necessary for such authority could never be in the bodies of white people. We just don't have it in us. The white body as a speaking subject-scholar does not exist outside the embodied anti-Blackness of whiteness I examine in this project. This is not an ethical but an epistemological issue. Moreover, the white scholar working in this field has to integrate a moral imperative (of engaging with Afro-pessimist theory beyond a mere nod of acknowledgment) with an epistemological impossibility - a situation for which dilemma is too small a word. The very attempt to integrate the imperative with the impossible is part of the specific modern epistemological project, which is built on the ideal of coherence (theoretical arguments, belief systems, subjectivities). Cherishing this ideal ignores the fact that in order to integrate both these positions, they must be imagined as existing on the same plane, even though the moral imperative has a completely different starting point and vector than the epistemological impossibility. Where the applied concepts perform and demand the destruction and collapse of the white author-subject, that subject paradoxically performs the maintenance of its own coherence in applying them. What then can a white person see in the void? What is the value of witnessing a cause that will not become a case? Specifically, how does the act of witnessing create the witnessed, and what libidinal economy and performance structure the relationship between the two? Is the impossible ethics behind this worth ignoring because of what might be won? (How) Can I speak about white ignorance without performing the claim for its transcendence? Is there any way for a white person to do this work without being - or thus becoming - an adventurer or a tourist? Is there any way to get aboard the ship and not be the captain, owner, investor, insurer? Is there, in fact, anything to be won? If so, for whom? Is white autocritique possible, and if so, what would it have to look like?

This project troubles the universalized, romantic concepts on which improv culture is based, leading to the complete dissolution of improv's referential and axiomatic framework without offering up anything in its place. I attempt to "learn how to go beyond ethnographic benevolence, as white European teachers, students, intellectuals, and how to practice disloyalty to white abjectorship and its ongoing power" (Broeck, "Legacies” 126). To do that, I mobilize Afro-pessimist concepts in a white discourse that needs to be troubled. Judgment calls about the performative or qualitative value of this project will vary. Do I risk too much for too little payoff? Can this project become part of an Afro-pessimist 
discourse, helping to generate a wider audience (in the improv sphere and in the disciplines I touch upon)? The individual white-positioned scholar cannot but become existentially brittle in becoming conscious of the fundamental antagonism of the modern world, working himself away and "wallowing in the contradictions" (Wilderson, "Wallowing"). Still, the aspiration to contribute something meaningful to Afro-pessimist discourse from a white position is not, or need not be, synonymous with an explicit or implicit call for white redemption or transcendence.

There is the cop-out of critical whiteness studies. But such a disciplinary label not only veils the fact that Black scholars have made this field possible; it is also structurally predisposed to re-center whiteness and tends to stay in the register of betterment, improvement, and progress. Moreover, moral judgment calls are often made in their name, or at least their discussions are grounded in moral implications, which makes it difficult to perform a structural analysis. I have taken care to avoid such gestures. This project is no fantasy of an antiracist transcendence of my own social position and racial privilege, nor does it mobilize the grammar of shame or guilt on the part of the subjects of my critique or for myself. It does not provide a method for so-called good anti-racist practice for white people, be it on the improv stage or in academic performance. I instead accept my structurally unethical position in the ethical conundrum, the epistemological mess of this politico-intellectual configuration, rather than pretending that this space is all tidied up - or could be via a critical academic performance. ${ }^{9}$

Building on the work and labor done in the field of Black studies always involves a double movement and contradictory performance for me. While in writing, speaking, or uttering I assert a social position of speakability that relies for

9 Sara Ahmed's "Declarations of Whiteness: The Non-performativity of Antiracism" is imperative in many ways. She argues succinctly that "declarations of whiteness" are both common and foundational for these disciplines as well as non-performative: "they do not do what they say" (introductory paragraph). Her critique of the term "critical" in the disciplinary nomenclature is on point:

I think the "critical" often functions as a place where we deposit our anxieties. We might assume that if we are doing critical whiteness studies, rather than whiteness studies, that we can protect ourselves from doing - or even being seen to do - the wrong kind of whiteness studies. But the word "critical" does not mean the elimination of risk, and nor should it become just a description of what we are doing over here, as opposed to them, over there. [...] The "critical" in "critical whiteness studies" cannot guarantee that it will have effects that are critical, in the sense of challenging relations of power that remain concealed as institutional norms or givens. Indeed, if the critical was used to describe the field, then we would become complicit with the transformation of education into an audit culture, into a culture that measures value through performance. (par. 8-10) 
its existence on Black non-speakability, I also acknowledge the work of scholars and bodies of theorization under the umbrella term of Black studies. Black studies enables us to know and understand the universalist holes in the Human/ist discourse of improv and its theorization, and any attempt at white autocritique must necessarily start there. However, underneath all such ruminations lies the fact that from the white position, it is epistemologically and ethically impossible to adjudicate on these questions in the first place. It is not up to me to decide whether my work is or isn't part of Black studies, (critical) whiteness Studies, or any other studies, or whether it advances one or more political aims, as diverse as they may be (the notion of advancement being problematic in itself). I can never assess whether it is meaningful academic work in solidarity or whether it has a contrary effect.

\subsection{Material}

In what narrative or argumentational units and planes do I find punctums? What is the material of this project? My strategy is similar to the delineation of the investigative territories themselves and has had a similar trajectory. At first, I sought to define a clear-cut canon of improv: historiographies, manuals, and writing from within. However, this soon proved to be too restrictive, too methodological to get a well-rounded idea about what I wanted to discuss. Such a selection was liable merely to reiterate idealized improv poetics rather than provide a ground for analysis of what is actually happening. Next, I figured I needed to talk to people, to improvisers. An improviser myself, I thought there would soon be common ground and a collective endeavor to find things out. Three factors stood in the way of working with qualitative interviews as a method. First, analyzing, interpreting, or even critiquing Black interviewees would make me an ethnographer at best and an obliterator of Blackness at worst. Second, very few white people were interested in talking about the subject. Third, the conversations mainly took place in the register of multiculturalism, diversity, stereotypes, and so on, which communicates poorly with my theoretical framework. So just as I (intuitively) made out three fields for investigation, I chose to work with relevant material wherever it struck me. Sometimes a section from an interview inspired a conceptual or theoretical finding; sometimes it emphasized one. The conversations illustrate or provide counterpoints to my findings, which may or may not subsequently be deconstructed. I am aware that this makes the project vulnerable to a superficial critique in terms of method. However, I must emphasize that the well-trodden paths of transparent, mechanically objective, and blindly-applied methods should be challenged on these 
grounds because they ultimately satisfy only the critic and may have little connection to the real world.

The material of this project, then, is improv discourse in its broadest sense. It involves historiographies, encyclopedias, and manuals, but also podcasts, blogs, and other sources. I work with anecdotes from improv practice related to me by improvisers, situations and occurrences in shows I have seen or been in, and workshops in which I have participated. From a vast textual body on improv or improvisation, this material is subjectively selected to draw a picture of improv that will help to ask the central question: why is it so white? In analyzing this picture, I go back and forth between punctums and studia, because, as it turns out, in order to understand how and why a punctum is effective, it helps first to understand the ground rules of the studium underneath the initial superficial interpretation. In this project, punctums are generally elements within improv discourse and practice (past and present) that speak to or resonate with Black absence, anti-Blackness, and racism, puncturing improv's otherwise almost mythologically idealized existence. These punctums shoot through many planes of discourse and practice. In essence, this project is designed to draw lines between the planes. What is often viewed as a two-dimensional and chronological reality (a studium) presents itself in a multidimensional and transtemporal dot-to-dot drawing. Some dimensions are closer to the immediately observable, intelligible surface. Others are only vaguely pointed towards. Some are obvious from Black-positioned viewpoints but effectively inaccessible for whites, while others present themselves to us as whites like a far-away light, the source of which we cannot even begin to interpret. Some we can immediately recognize and address with the language at our disposal, while others may need more theorization, empirical findings, or the willingness and affective capacity for genuine autocritique.

Accordingly, I engage with these discursive units on various levels of abstraction. When working in and around the three (intuitively selected) conceptual pillars of improv discourse and their axiomatically-posited disciplinary ground intuition, play, and humor - I engage with the ways in which they speak through and are made manifest in improv practice and discourse. I challenge the central tenets of improv - that is, the historical trajectories of phenomena or ideas - asking what exactly we understand by them, how they came into our world, and how else we might conceive of them. Only by questioning and challenging the meanings of these conceptual tenets can I get closer to improv's deep-seated linguistic and affective structures. As a result, the project often far exceeds the limits of improv, expanding beyond its existence as a manifest cultural phenomenon. While I set out to investigate the cultural phenomenon of improv, then, I also 
offer a discussion of the auto-institutive mechanisms of whiteness as articulated through improv.

\subsection{Chapter survey}

I begin my argument in Chapter 2, "US Improv Comedy and Race - A Sketchy Report," by laying out the general territory of investigation named improv. By improv, I mean not solely an aesthetic modality or stage practice but a cultural sphere that involves interrelated actual, social, and discursive spaces. For me, that discursive space includes everything from blogs to podcasts to printed how-to manuals and various almanacs. For this project, improv discourse denotes everything said about improv from within and without. I also differentiate this project from other scholarly engagements with improv, improvisation, improvised performance, and other variants or degrees of abstractification. I ground this project in the real-world thoughts, lived experiences, and perspectives of improvisers, who (at the time of the interviews) have mainly lived and worked in Chicago. I also draw examples from online debates about the racialized culture of improv. I have taken great care to keep the material grounded and connected to the actual improv reality.

First I will look at Chicago, demonstrating how this mecca of improv is an articulate manifestation of the way that social capital transforms into real career opportunities for comics. I mobilize the criticism advanced under the metaphor of a cult, which has often been directed against the improv scene. Then I move on to consider how race, and Black absence specifically, features in contemporary improv discourse, reading relevant discursive punctums as symptoms that are always overridden and brushed aside by the socioaesthetic ideals in which improv is embedded. Rather than marginalizing Black absence as an exception to the rule, I center this absence, looking at how improvisers today make sense of this absence and reading through the central topoi of this argument: concepts of (lack of) exposure, representation, economic factors, and so on. However, most of these arguments are presented in the registers of diversity or segregation - concepts about which those I interviewed held a vast range of nuanced positions. Throughout the years working on this project, I have come to adopt a different position on these questions. I present a critique of diversity via Jaye Austin Williams, Frank Wilderson, Karen and Barbara Fields, and Charles Mills, leading up to a consideration of Calvin Warren's theorization of a politics of hope. On this ground, the chapter ends with more examples of how anti-Black racism is a present absence in improv, arguing that there is indeed something 
specific in improv that makes it particularly liable to racialization and antiBlackness.

Chapter 3, "Truths for Whiteness," presents a larger theoretical framework with which to approach the most fundamental points of reference of improvised theatrical play in improv practice, poetics, and discourse: the Human. Rather than idealizing this modern Human subject or accepting the romanticized axioms that regularly accompany the concept, I take up Sylvia Wynter's analysis of how the modern Human functions as a tool with which culturally specific Western Man "overrepresents itself as if it were the human itself” ("Unsettling” 260) while making this historically specific modality invisible to those who understand and experience themselves through it. Wynter shows that modernity does not bring about a discursive revolution of generalized human self-knowledge but rather a transumption of terms that still draws on a discursive matrix based on dichotomies of perfection and imperfection, heaven and earth, motion and stasis, high and low, reason and irrationality, Gods and beasts. Wynter traces this transumptive trajectory back to a Hellenistic "master code" on which, as she argues, modern whiteness has been modeled as a human ideal ("Unsettling" 263). Within this code, Blackness functions as the sphere of white Humanity's absolutized other. I follow Wynter in her conceptualization of being human as a praxis in bios-mythoi hybridity. Taking my cue from what she develops as the sociogenic principle after Fanon, I relate her theory to the disciplinary frameworks of psychoanalysis and embodied cognition. I understand both to be instrumental in Wynter's overall aim to conceive of being human as praxis rather than as noun. The significance of Wynter's array of concepts for this project cannot be overemphasized - most centrally the notion of transumption (borrowed from Harold Bloom), but also the sociogenic principle, being human as praxis, her in-depth analysis of the discursive matrix, and the alternative pathways she opens up to understand what being human in bios-mythoi hybridity may entail. While I will occasionally mark the most immediate connections, Wynter's work has been instructive in many regards for this entire endeavor. From here, I turn to Frank Wilderson's notion of libidinal economy and the symbolic and affective role of anti-Black enslavement for the making of the white modern subject's psyche. I consider more explicitly those theorists associated with Afro-pessimism and emphasize the libidinal dimensions of the modern subject, whose coherence I argue is entirely dependent upon discursive and affective anti-Blackness, the social death of Black-racialized people, and the longue durée or "afterlife of slavery," a term coined by Saidiya Hartman (Mother 6).

Drawing on Wynter's dictum that "[w]ith being human everything is praxis" ("Catastrophe" 34), I introduce the concept of anti-Black abjection as theorized by Broeck in acknowledgment of but distinct from Julia Kristeva's concept of the 
“abject.” In this project, I think Kristeva's and Broeck's usages of the term abjection alongside each other. Kristeva develops her concept within film theory, and I suggest that the affects engendered by perceptive abjection are important to understand, or at least to keep in mind when reading specifically anti-Black abjection as a continual praxis of being human in Western modernity, as Broeck does. With Broeck and Kristeva, I develop the historically and culturally specific notion of an embodied modern subject-effect that must be continually engendered to maintain individual, social, and political coherence. In Western modernity, this subject-effect is structurally always already achieved by anti-Black abjection qua action, perception, and imagination of fungible Blackness that is open for gratuitous violence of all kinds. In a section of Chapter 3 titled "Embodying anti-Black abjection," I look into how anti-Black libidinality and the idea of a subject-effect can be discussed in the language of embodied cognition and neuroscience. Drawing mainly on Antonio Damasio's classic and still highly influential concepts, I consider emotional, feelings, and somatic markers. I understand the linkage between psychoanalysis and embodied cognition as putting into practice Sylvia Wynter's model of being human in bios-mythoi/logos hybridity. I use both psychoanalytic and neuroscientific concepts to argue for the cultural specificity of the discursive (and affectively biologized/naturalized) structure of Western modernity, leading up to reading Blackness as a somatic marker - both specific and concrete as well as vague, undefined, and potentially expansive through which anti-Black abjection happens. Linking this back to Kristeva's notion of a subject-effect, which I reframe as a subject-aeffect, I theorize white solipsist subjectivity in Black presence and absence as a discursive and biological predisposition for voluntary or involuntary anti-Black thought, affect, and action. At the end of this subsection stands a metatheoretical consideration of Kristeva's abjection as an already-raced concept. I engage with the argument that the application of abjection runs the risk of circular reasoning: the concept seems so apt for analyzing racism because it is itself a raced concept, starting from the condition it seeks to critique. I preempt this criticism by returning to the decidedly (and exclusively) anti-Black abjection of the modern West understood as an act rather than a feeling, as well as to Wynter's conception of being human in bios-mythoi hybridity and her post-Fanon theorization of the "study of the Word" as a scholarly method. Unlike Kristeva, I do not aspire to conceive of or engage with a fixed ontology of human being.

In the next section of the chapter, "Modern Popular Culture as Blackness," I lay out the field of popular culture understood as a disciplined territory in which improv exists. However, before looking into improv as such, I put the popular itself under scrutiny by reading it through the lens of modernity's anti-Black abjective structure. After a brief consideration of the ways in which the rhetoric of 
appropriation is insufficient when it comes to anti-Blackness, I historicize the birth of US popular culture (and, by extension, popular culture in the modern West) in the spectacle of the auction block. I draw mainly on Saidiya Hartman's invaluable archival work in Scenes of Subjection. This discussion also further defines the fine line between white witnesses to and spectators of dehumanized Black suffering: what Hartman discusses as the "terror of pleasure" and the "pleasure of terror" (Scenes 32), and the white subject's incapacity for empathy when confronted with the suffering of Black bodies. I look at the way lynching parties functioned as popular cultural events and galvanized the creation of a popular as such. I go on to consider James Baldwin's short story "Going to Meet the Man" as an in-depth analysis of how the "pleasure of terror" experienced by white subjects through anti-Black abjection is central in the development of US popular culture. As Baldwin's story contains graphic descriptions of dehumanizing violence against Black people, the analysis is preceded by a trigger warning. A subsequent discussion of minstrelsy creates a more obvious connection between my project and what is more commonly known as popular culture. In minstrelsy, we find an overt articulation of anti-Black abjective culture as well as the aesthetics of stage performance in a way that white readers will find more recognizable. In this section, I mainly draw on Mel Watkins's extensive monograph On the Real Side (1999); unlike its subtitle suggests, the book is not (only) A History of African American Comedy, but also provides ample material for understanding US popular culture at large.

I conclude the section by looking at how popular culture has been treated in contemporary scholarship, arguing that proponents like Richard Shusterman draw on the same affective and matrical assumption as popular culture's classic opponent, Theodor Adorno. The discussion here takes the shape of a close reading of the latter's infamous criticism of jazz (once again, some might say) within the critical framework of Afro-pessimism and the conceptual toolkit developed through this project. The underlying hypothesis is that Adorno can make his generalized arguments about popular culture only by way of abjecting and - in the strict sense - dehumanizing Blackness. Grounded in this analysis, I suggest that all popular culture is both Black and anti-Black, that the popular is and has always been a sphere for white, sociopolitical negotiation that substantially references and works with Black cultural production but never addresses this very axiomatic assumption. Taking my cue from and in conversation with Fumi Okiji's Jazz as Critique, I address Adorno's arguments about jazz outside the moral or judgmental register while acknowledging the racism and anti-Blackness neces- 
sary to understand the full dimension of his argument. ${ }^{10}$ In a coda, I argue that Adorno's positions on popular culture are dated in the sense that we had better take popular culture as a fact rather than a romanticized (or scorned) space of political negotiation. I bring Adorno into conversation with Ronald Judy, who discredits such defenses of modern, individualist subjectivity as regressive. Seeing the difference between Adorno's holding on to modern Human subjectivity and Judy's gestures towards a different, affect-based idea of human being altogether opens up significant conceptual pathways.

In the next three chapters, I work around what I have defined as the foundational concepts in improv practice and poetics. Chapter 4, "Who Speaks?," engages with the idea of intuition. I begin by reading the aesthetic and philosophical climate of improv's emergence, which cultural theorist Daniel Belgrad has defined as an epoch and aesthetic configuration named the "culture of spontaneity." In willful ignorance of potential friction between the sphere of the popular and the assumed sphere of art, I lay out how the axiomatic similarities that underly those post-World War II artistic practices and the popular, humorous world of improv are very much the same; both seek to vivify an uncritical conception the Human in a conceptually esoteric but sincerely applied neo-vitalism. With recourse to Donna V. Jones's The Racial Discourses of Life Philosophy (2012), I demonstrate how vitalism has been inherently racial from its inception. Its turn-of-the-century and early twentieth century manifestations in particular most notably its articulation by Henri Bergson - were the ground for the circulating aesthetics in which improv could flourish. These neo-vitalisms worked overtly on anti-Blackness for theorizing and propagating the invigoration of white but universalized subjectivity at a time when human beings were understood as automatons. Given that anti-Blackness is the formative ground for this neo-vitalism, anti-Black abjection should be visible in both art and popular culture. I show how this proves true not only in aesthetic performative practice but also in its theorization, demonstrating how the very Blackness that gave life to, inspired, and enabled philosophies, poetics, and practices has been effaced. While the Black-as-Slave figure has been mobilized as a central metaphor for what the white subject does not want to be, Blackness itself has been obliterated. The historical contexts of Black cultural production have been willfully thrust into oblivion, and its principles are turned into an all-encompassing American-

10 I hold Toni Morrison's assertion about the literary imagination to be just as valid for the scholarly one: "A criticism that needs to insist that literature is [...] 'race-free' risks lobotomizing that literature, and diminishes both the art and the artist" (12). 
ness. By close reading a passage from Sam Wasson's Improv Nation (2017), I demonstrate how improv discourse does this explicitly.

In the second section of the chapter, "Intuition and Abjection," I zoom in on the notion of intuition. The concept is mobilized by improv and within the broader culture of spontaneity to gain access to something higher (truth or design), or, from another perspective, to something lower (the unconscious). I consider Viola Spolin's classic writing on intuition in Improvisation for the Theater (1963) as well as another seminal improv text, Truth in Comedy (1994), which represents Del Close's approach, showing how two of the most influential teachers of improv draw on the concept of intuition. Drawing on Damasio, Wynter, Mills, and Warren, I then make a case for understanding intuition not so much as a pathway for an unconscious potential resigning within $u s$, but as a mode that allows white people to generate a subject-aeffect - the linguistically arbitrary but biochemically real auto-imagination of ourselves as complete, integral entities - and which by necessity draws on anti-Blackness. I thus argue for the cultural specificity of a white intuition as opposed to a generalized human intuition assumed to bring us all together, partaking in a Politics of a Truth we are falsely assumed to share as a universal. Towards the end of the chapter, I return to the modern libidinal structure, speculating about whether the fact that people achieve a subject-aeffect qua culturally specific anti-Black abjection might more radically reveal that for us white people, intuition as such is anti-Black. I ask whether it is reasonable to distinguish intuition as such from intuition qua Blackness as a contingent, arbitrary signifier. That we can generate a subject-aeffect through intuition in the first instance (not the second, cultured one) is also based on the fact that we white people can only know ourselves as a split person inhabiting the world of reason and the world of beasts. For us modern white subjects, this very split can only exist in anti-Blackness; if not for anti-Blackness, then, intuition would have another affective effect for us. It would not necessarily make us feel whole. It might not even make us feel anything at all.

Chapter 5, "Abjection in Play," deals with the second discursive pillar of improv: play. I draw on D. W. Winnicott's theory of play and the attached concepts of transitional objects or phenomena. With Winnicott, I define play as a space in which the fictional and the real, the affective and the symbolic are activated simultaneously, making it a highly fitting concept for analyzing improv practice in general. For the infant, the objects or phenomena at the center of abjection move back and forth between these two spheres. Winnicott describes these objects as the first properties of the child, and their movement back and forth between the real and the fictional is part of its subject formation. They are transitional in the sense that they perform a central function in the transition from union with the mother into the symbolic realm. Activating the sphere of symbolic non-existence 
and the exit from non-symbolic bliss in playing is "essentially satisfying [...] even when it leads to a high degree of anxiety" (Winnicott 70). At this juncture, I link Winnicott's theory of play to Kristeva's understanding of abjection. Kristeva too builds on the notion of a child rejecting a mother's breast, which for Winnicott functions as a (symbolic and real) referent for which the transitional object or phenomenon has a (symbolic and real) stand-in function. Winnicott's theory of play is insightful in two ways. Most importantly, the transitional object or phenomenon shares central characteristics with Blackness. It provides the child with an experience of omnipotent control both over the object and its subject state. Through transitional phenomena, the child generates and rehearses its (primal) subject-aeffect. (Winnicott does not restrict this to physical objects, even though these are his primary concern. He also considers transitional phenomena, by which he means songs, motions, and other forms of play. Very much like the mobilization of intuition, the notion of Black transitional phenomena allows us to think about the activity of play in the same way we can think of a white agent's affect when listening to R'n'B or watching interracial porn.) Additionally, Winnicott's transitional object or phenomenon can be related to the anti-Black abjectorship of white subjectivity because it is always property for the child.

In improv discourse, the phrase "to treat somebody like a prop onstage" is common. I offer a close reading of the human body as a theatrical prop in a section titled "Improvising property." What does it mean to have a prop on stage? How can a human body be made to function as a prop in a scene? How does anti-Blackness feed into this aesthetic and metaphoric propertization of human bodies on the stage? After establishing the conceptual simultaneity of the literal and metaphorical understandings of a human body as a theater prop, I consider in more detail functional and communicational theories of property from Margaret J. Radin and Carol M. Rose. As implied in the German term for prop - Requisite, which comes from Latin and roughly means requirement or necessary thing - I ponder how the human-as-prop(erty) is a necessity for (white) improvisation based on a Western subject that requires possession and power over things and bodies to maintain itself.

Chapter 6, "Funny Matter," addresses the most obvious pillar that structures improv discourse: humor. On the grounds of the libidinally anti-Black structure of the modern West, I consider Freud's traditional analysis of joke work, the modus operandi of which he compares to dreamwork, and its specific mechanics of jouissance. I focus on what he calls the tendentiousness of jokes, the libidinal undercurrent that, according to Freud, drives all humor - regardless of how abstract or aesthetic it may fashion itself. I link this tendentiousness, its communicative functions, and the way it engenders sociality (both temporary and beyond time) to the anti-Black abjective principle. I suggest that the specific tendentious 
power of humor in social situations predetermines anti-Blackness, at least whenever Blackness comes up in a staged and performed situation. Afterwards, I enter a metatheoretical register and consider incipient continental humor theory. I demonstrate how anti-Blackness has metaphorically and non-metaphorically engendered the theorization of humor most explicitly and with it the theorization of the Human - the a priori referent (and logical end) of all humor studies. In Bergson, who surprisingly reappears in this discussion, we find an almost textbook anti-Black humor theory on the grounds of his universalist, neo-vitalist humanism, as discussed in Chapter 4. While with Freud I cover the so-called release theory of humor, with Bergson I engage with what has come to be classified as a superiority theory of humor. I argue strongly that in theorizing humor, there is no justifiable legitimation for such differentiation, extending this argument to the allegedly abstract and aesthetic approaches of so-called incongruity theories, which are the ground of most contemporary humor studies. I trace part of the historical trajectory of this strand of humor theory and discuss how it has always been intertwined with other theorizations of humor, arguing that there is no reason to distinguish them from one another - even if only for heuristic reasons. I further suggest that, paradoxically, such heuristic distinctions mystify the fact that in effect and in its historical trajectory, the ground for such incongruity has always been the foundational antagonism of the white Human subject and the de-Humanized Black body. This discussion of humor is summed up in a section titled “'Where is your brain from?' Blackness-as-superpower.” What might appear as a final turn toward an optimistic Afrofuturism at the end of the project is rather a consideration of the ambivalent, contradictory, and hard-to-bear humorous powers that the foundational difference between $\mathrm{Hu}$ manity and non-Humanity holds for those positioned as Human. The Blackness-as-superpower topos came up in numerous conversations with improvisers in Chicago, and involves all the messy, contradictory, hopeful, and pessimistic positions and realities that have driven this project. Following the previous theoretical analyses, this section re-grounds the project in the realities of improv comedy. It stages the ways in which being Black in improv for some of those who live this discursive impossibility "is almost like a handicap that you have to make a superpower. If you're the only black person in a scene, you're automatically driving that scene. It's not fair, but it's true" (Joel Boyd, personal conversation). ${ }^{11}$

11 Joel Boyd is an improviser, writer, and stand-up artist. He wrote for Drop the Mic (2018, TBS/ TNT) and Earth to Ned (2020, Disney+). He also created, directed, and wrote for the web series Sad-Ass Black Folk. Boyd now lives in LA. Our conversation took place in March 2015 in Chicago. The material used in this project was authorized by Boyd via email on 15 November 2019. 